\title{
ARTICLE
}

\section{Towards a cross-disciplinary framework for promoting youth wellbeing}

\author{
Amanda Ng · Dianne A. Vella-Brodrick
}

\begin{abstract}
The youth wellbeing literature draws upon the fields of Positive Education, Positive Youth Development, Social and Emotional Learning, Coaching and Mentoring Psychology and Quality of Life, collectively referred to as the Youth Wellbeing Fives (YWB Fives). Despite their individual efforts to promote mental health and address mental health issues, no study to date has explored their collective contributions (intersections) towards this goal, nor has a framework been developed to understand the benefits of collaboration between youth wellbeing scholars from different fields. This paper develops a framework for promoting the cross-disciplinary study of youth wellbeing, and critically reviews the contributions of individual and collective YWB Fives to enhancing the wellbeing of young people. Given their complementary approaches and combined influence on successful interventions, we illuminate possibilities for intersections to exist among the YWB Fives. Insights gained have various research and practical applications; these include providing a rationale for future youth studies to empirically measure intersections among the YWB Fives, and encouraging the development, delivery and evaluation of cross-disciplinary interventions to ensure widespread access to wellbeing services by all young people.
\end{abstract}

Keywords: youth; wellbeing; mental health; cross-disciplinarity

\section{Introduction}

Wellbeing is a state of 'feeling good', which includes notions of happiness, contentment and engagement; and 'functioning well', which encompasses concepts such as purpose, positive relationships and sense of control (Huppert, 2009). Although the goal of wellbeing applies to individuals across the lifespan, efforts to promote youth wellbeing (YWB) is particularly crucial given the prevalence of adolescent mental health issues (Eckersley, 2011) and the role of thriving youth in building civil and productive societies (Lerner, 2004).

In line with this importance, considerable progress to advance YWB and its understanding has been made within five major research fields: Positive Education (PE) (Oades, Robinson, \& Green, 2011), Positive Youth Development (PYD) (Benson, Scales, Hamilton, \& Sesma, 2006), Social and Emotional Learning (SEL) (Osher et al., 2016), Coaching and Mentoring Psychology (CAMP) (Van Nieuwerburgh, 2012) and Quality of Life (QOL) (Wallander \& Koot, 2016) - collectively referred to hereinafter as the 'Youth Wellbeing Fives' 
(YWB Fives). Although these fields differ at the individual level, such as in terms of their target wellbeing dimensions and target setting (for details, see Table 1), the YWB Fives are united by the collective goal to promote YWB. Thus one might expect scholars across YWB Five fields to work together in pursuit of $\mathrm{YWB}$, and for research across these fields to intersect within the broader YWB literature.

\section{Table 1}

Overview of the Youth Wellbeing Fives

\begin{tabular}{|c|c|c|c|c|}
\hline Field & $\begin{array}{c}\text { Primary } \\
\text { Emphasis/Approach }\end{array}$ & $\begin{array}{l}\text { Key Wellbeing } \\
\text { Dimensions }\end{array}$ & $\begin{array}{c}\text { Target } \\
\text { Population(s) }\end{array}$ & Target Setting(s) \\
\hline $\mathrm{PE}^{\mathrm{a}}$ & Promotion & $\begin{array}{l}\text { Social, emotional, } \\
\text { cognitive, spiritual, } \\
\text { psychological and } \\
\text { academic wellbeing }\end{array}$ & $\begin{array}{l}\text { Individuals in school } \\
\text { settings, including } \\
\text { students (children and } \\
\text { adolescents), school } \\
\text { staff and school } \\
\text { community members }\end{array}$ & $\begin{array}{l}\text { School, classroom, and } \\
\text { other learning } \\
\text { environments including } \\
\text { tertiary institutions }\end{array}$ \\
\hline $\mathrm{PYD}^{\mathrm{b}}$ & Promotion & $\begin{array}{l}\text { Social, cognitive, } \\
\text { psychological and } \\
\text { civic wellbeing }\end{array}$ & Adolescents & $\begin{array}{l}\text { Family, peer, school, } \\
\text { neighbourhood, } \\
\text { community and cultural } \\
\text { contexts }\end{array}$ \\
\hline SELc & Prevention & $\begin{array}{l}\text { Social, emotional and } \\
\text { cognitive wellbeing }\end{array}$ & $\begin{array}{l}\text { Children and } \\
\text { adolescents in school } \\
\text { settings, although SEL } \\
\text { can also apply to the } \\
\text { adults in young } \\
\text { people's lives }\end{array}$ & $\begin{array}{l}\text { School, classroom and } \\
\text { other learning } \\
\text { environments including } \\
\text { afterschool settings }\end{array}$ \\
\hline CAMPd $^{d}$ & $\begin{array}{l}\text { Promotion } \\
\text { (Coaching) } \\
\text { Prevention } \\
\text { (Mentoring) }\end{array}$ & $\begin{array}{l}\text { Various depending } \\
\text { on the intervention, } \\
\text { including physical, } \\
\text { social, emotional, } \\
\text { cognitive, } \\
\text { behavioural and } \\
\text { academic wellbeing }\end{array}$ & $\begin{array}{l}\text { Various including } \\
\text { children, adolescents, } \\
\text { adults, non-clinical and } \\
\text { disadvantaged/at-risk } \\
\text { populations }\end{array}$ & $\begin{array}{l}\text { Various including } \\
\text { community, workplace, } \\
\text { school, afterschool and } \\
\text { sports settings }\end{array}$ \\
\hline QOL & $\begin{array}{l}\text { Promotion (e.g., } \\
\text { Subjective } \\
\text { Wellbeing) } \\
\text { Prevention (e.g., } \\
\text { Health-related QOL) }\end{array}$ & $\begin{array}{l}\text { Physical, social, } \\
\text { emotional, spiritual, } \\
\text { material and } \\
\text { productive wellbeing }\end{array}$ & $\begin{array}{l}\text { Patient and general } \\
\text { adult and child } \\
\text { populations }\end{array}$ & $\begin{array}{l}\text { Health care and general } \\
\text { population settings }\end{array}$ \\
\hline
\end{tabular}

Note: Primary Emphasis/Approach lists the primary and common strategies used, not exclusively, by the Youth Wellbeing Fives. ${ }^{a}$ Positive Education; ${ }^{b}$

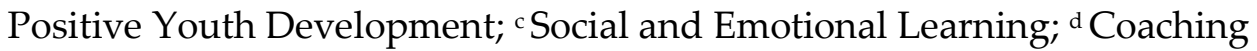
and Mentoring Psychology; ${ }^{\mathrm{e}}$ Quality of Life. 
Two questions that arise from this perspective are (1) What are the benefits of crossdisciplinary collaboration for YWB?; and (2) "Do the YWB Fives collectively contribute (intersect) to promoting YWB?". This paper attempts to address these questions by first developing a framework for understanding the benefits of cross-disciplinary collaboration for enhancing $\mathrm{YWB}$, and using this framework as a basis for exploring the potential intersections among the YWB Fives. In doing so, we review key individual and collective contributions of the YWB Five fields to the YWB literature. This paper is intended to provide a snapshot rather than a comprehensive analysis of their contributions, as the latter would require more attention than can be given in a single paper. We also focus on the aims of YWB to enhance wellbeing and promote mental health, though we acknowledge the prevention aims of the field to concurrently tackle issues of mental ill health. We maintain throughout that the YWB literature is inherently cross-disciplinary, thus efforts to promote YWB need to be informed by multiple fields and the unique perspectives they offer.

\section{The Need for A Cross-Disciplinary Framework}

Despite potential for integrating multiple literatures on YWB (Tolan, Ross, Arkin, Godine, \& Clark, 2016), a framework for understanding the benefits of cross-disciplinary collaboration for YWB is still lacking. While there may be situations in which a singledisciplinary focus is preferred, such as when time constraints call for rapid knowledge accumulation within a specific domain, there are reasons why research should, at other times, favour a cross-disciplinary approach. This section presents a useful framework for understanding the advantages of approaching YWB scholarship from a cross-disciplinary perspective, which include but are not limited to: (1) capturing the complex nature of $\mathrm{YWB},(2)$ solving the grand challenge of YWB promotion, (3) creating a shared language around YWB that unifies understanding of the phenomenon, and (4) improving the quality, impact and efficiency of YWB research.

Capturing the complex nature of youth wellbeing. Youth wellbeing is complex concept involving multiple dimensions and numerous connections to other phenomena. Evidence for its multidimensionality is found in its alignment with models such as PERMA, in which psychological wellbeing encompasses five core elements of Positive Emotions, Engagement, Relationships, Meaning and Accomplishment (Kern, Waters, Adler, \& White, 2015), and the SEL framework proposed by the Collaborative for Academic Social and Emotional Learning (CASEL) (2005), in which healthy youth development comprises multiple social, emotional and cognitive competencies. The complexity of YWB is additionally expressed in its diverse connections with other phenomena, including perceived health, risky behaviours, identity and purpose (Hoyt, Chase-Lansdale, McDade, \& Adam, 2012; Sumner, Burrow, \& Hill, 2015). Given that expertise from different domains is required to make sense of complexity (Vicens \& Bourne, 2007), we propose that integrating YWB research across multiple fields and harnessing their collective resources could help better understand YWB and support its promotion.

Solving the grand challenge of youth wellbeing promotion. Cross-disciplinary collaboration is critical for solving complex, global issues in society, otherwise known as 'grand challenges' (O'Rourke, Crowley, \& Gonnerman, 2016). There are several criteria by which to 
distinguish grand challenges: broad applicability, ability to manifest at different levels of scale, and the interest they attract in politically and financially supporting research in providing a solution (O'Rourke et al., 2016). Based on these criteria, indications in the literature suggest that the goal of promoting YWB is a grand challenge remaining to be solved.

Supporting the first criterion, YWB has potential applications in a number of contexts; for example, education (Seligman, Ernst, Gillham, Reivich, \& Linkins, 2009), youth development (Olsson, McGee, Nada-Raja, \& Williams, 2013) and biological contexts of genetics and heritability (Gigantesco et al., 2011). Fulfilling the second criterion, YWB operates at various levels of scale including biological, cultural and historical (Lerner, 2004) and, as suggested by research on youth resilience, within a hierarchy of ecological systems ranging from the individual level through to broader microsystem and macrosystem levels (Sapienza \& Masten, 2011). The third criterion of grand challenges is also satisfied by the YWB literature, as indicated by calls for greater policy coordination to monitor the global health of young people (Patton et al., 2012) and governmental efforts to fund research on YWB (Milnes et al., 2011). Scholars within the youth studies literature have also documented the role of organisations with significant policy influence in measuring YWB (McLeod \& Wright, 2016). As crossdisciplinary collaboration is a necessary condition for solving grand challenges (O'Rourke et al., 2016), we believe that meeting the grand challenge of YWB promotion would require leveraging the contributions of multiple fields focused on YWB; fields such as the YWB Fives.

Creating a shared language around youth wellbeing. Scholars who engage in authentic interactions with one another may develop a shared language that serves to promote their understanding of a given topic (Jeffrey, 2003). From this perspective, encouraging YWB scholars from different fields to collaborate could result in the co-creation of a language with which to discuss and understand YWB among the group. Using clear language that others can understand is key to success in cross-disciplinary relationships (Knapp et al., 2015), whereas ambiguous and imprecise terminology easily lends itself to misunderstanding (Lilienfeld et al., 2015). Promoting successful cross-disciplinary collaboration among YWB scholars is thus central in this regard, not only when it comes to sending clear messages to the scholarly community but also to laypeople who may be unfamiliar with scientific and academic jargon.

Improving the quality, impact and efficiency of research. Cross-disciplinary collaboration can improve the quality, impact and efficiency of research. Studies have shown that highly interdisciplinary or integrated publications tend to score more favourably on measures of research quality and impact (Franceschet \& Costantini, 2010; Porter, Garner, \& Crowl, 2012), and that scholarly collaboration can accelerate research by synthesising knowledge across diverse fields and increasing potential for fortuitous discoveries (Hackett, Parker, Conz, Rhoten, \& Parker, 2008). Group diversity has also been observed to enhance productivity (Barjak \& Robinson, 2008), although the crucial question may not be whether but under what conditions diverse efforts promote efficiency. Coordination level (Cummings \& Kiesler, 2007) and interpersonal skills (Vicens \& Bourne, 2007), for instance, have been identified as important determinants of the benefits of cross-disciplinary collaboration for research efficiency. In the context of YWB research, these findings suggest that integrating the work of multiple fields focused on YWB can advance the literature by improving its research quality, impact and efficiency. 


\section{Individual Contributions of the Youth Wellbeing Fives}

Given the benefits of cross-disciplinary collaboration, we now turn our attention to considering PE, PYD, SEL, CAMP and QOL as candidates for exploring the intersections in YWB research. In this section, we review key theoretical and empirical contributions of the YWB Fives to promoting YWB in turn.

Positive Education. Defined as education for both traditional skills and wellbeing (Seligman et al., 2009), the field of PE seeks to promote positive mental health by grounding best-practice teaching methods in evidence-based principles of Positive Psychology (Norrish, Williams, O'Connor, \& Robinson, 2013). As an indication of its success, PE targets and has been implemented across a range of learning environments including primary, secondary and tertiary-level institutions (Jarden \& Jarden, 2015).

Theoretical contributions. Foundational theories of Positive Psychology, including Flow Theory (Nakamura \& Csikszentmihalyi, 2009), Strengths Theory (Peterson \& Seligman, 2006) and the Broaden-and-Build Theory of Positive Emotions (Fredrickson, 2001), have guided efforts in PE to improve YWB in various educational contexts (Norrish \& Vella-Brodrick, 2009; Reschly, Huebner, Appleton, \& Antaramian, 2008). Theoretical frameworks for promoting school-wide wellbeing have also emerged within the field of PE. Geelong Grammar School in Australia, for instance, has developed an exemplar PE framework for promoting the wellbeing of school students, parents and staff across the domains of Positive Emotions, Positive Engagement, Positive Accomplishment, Positive Purpose, Positive Relationships and Positive Health (Norrish et al., 2013). Other noteworthy frameworks offered by PE include the Positive Educational Practices Framework, which draws upon positive psychology scholarship to support student wellbeing, and PROSPER, which identifies Positivity, Relationships, Outcomes, Strengths, Purpose, Engagement and Resilience as key pathways to student flourishing (Noble \& McGrath, 2008, 2015).

Empirical contributions. Positive education interventions have shown to significantly improve YWB in a host of areas including self-esteem, self-acceptance, satisfaction, and positive and negative affect, with effects appearing stronger for particular youth groups such as those at risk (Waters, 2017). Furthermore, a randomised controlled evaluation of the Strath Haven Positive Psychology Programme revealed increases in programme participants' levels of school engagement and school enjoyment, relative to those who did not receive the programme (Seligman et al., 2009). More recently, Vella-Brodrick, Rickard, and Chin (August 2014) evaluated the effectiveness of PE at Geelong Grammar School's Timbertop campus, and found compelling evidence that PE can benefit students' mental wellbeing, foster a sense of student accomplishment and connection with others, and equip students with practical, positive strategies to effectively manage everyday life. A more comprehensive list of existing PE curricula has been compiled by Slemp et al. (2017).

Positive Youth Development. The field of PYD, as defined by youth studies scholars, represents a shift in dominant conceptualisations of young people largely fueled by changing social and economic conditions over time (Sukarieh \& Tannock, 2011). This shift sought to move away from viewing youth as 'problems to be managed' to 'resources to be developed' (Roth \& Brooks-Gunn, 2003). As a field of inquiry, PYD seeks to foster YWB by building upon 
the positive individual and social assets possessed by adolescents that support their healthy development into adulthood (Eccles \& Gootman, 2002). The field operates from an ecologicaldevelopmental perspective and targets multiple contexts in which youth are embedded, including family, peer, school, neighbourhood, and broader community and cultural contexts (Benson et al., 2006).

Theoretical contributions. The field of PYD contributes a grand theory of youth development that integrates principles of human development, community organisation and development, and social and community change (Benson et al., 2006). This theory emphasises the plastic nature of YWB and its potential to strengthen over time; it proposes that PYD is affected by the opportunities provided and made accessible to young people in their communities and that such person-context relations are subject to change across the life span. Wellbeing also appears to be an important overarching theme across many PYD frameworks: The Four Essential Elements, for example, links positive youth outcomes to experiences of Belonging, Mastery, Independence and Generosity, which can be measured using wellbeing indicators such as self-esteem and desirability to help others (Kress, 2003). The Five Cs model, on the other hand, situates PYD within the broader context of wellbeing and posits that YWB can be assessed at any time by measuring the overall contributions of five key domainsCompetence, Confidence, Connection, Character and Caring, and more recently, Contributionto a young person's development (Lerner, 2004).

Empirical contributions. The most empirically supported PYD framework is The Five Cs (Heck \& Subramaniam, 2009). Researchers have found associations between PYD, as indicated by the Five Cs, and positive youth outcomes such as higher levels of civic identity and civic engagement, and decreased engagement in risky behaviours (Bobek, Zaff, Li, \& Lerner, 2009; Jelicic, Bobek, Phelps, Lerner, \& Lerner, 2007). Positive outcomes have been reported in evaluations of in-school and out-of-school PYD programmes (Eichas et al., 2010; Tebes et al., 2007), and further support for the contributions of PYD programming to YWB stems from a meta-analysis demonstrating significant improvements on measures of psychological adjustment (Ciocanel, Power, Eriksen, \& Gillings, 2017). While more rigorous research is needed to confirm the effectiveness of PYD interventions (Ciocanel et al., 2017), current findings generally support PYD programming as a promising strategy for promoting YWB outcomes (Catalano, Berglund, Ryan, Lonczak, \& Hawkins, 2004).

Social and Emotional Learning. Social and Emotional Learning describes a universal process of acquiring the skills necessary for managing emotions, building relationships and solving problems effectively (CASEL 2005). Grounded largely in preventive and resilience research, SEL's mission is to equip young people with the critical SEL skills needed to bounce back from adversity (Humphrey, 2013). SEL instruction is relevant to all students including those at risk or exhibiting negative behaviours (Zins \& Elias, 2007), and is therefore applicable to a range of student-centered environments such as schools, classrooms and afterschool settings. While students tend to be the primary recipients of SEL programming, SEL may also involve the adults in young people's lives and include their parents and members of the wider community (Humphrey, 2013).

Theoretical contributions. The field of SEL offers several theoretical frameworks for organising strategies to support young people's social and emotional development. These 
include the integrated SEL framework proposed by CASEL (2005), which identifies five interrelated competencies underpinning high-quality SEL programming (Self-Awareness, SelfManagement, Social Awareness, Relationship Skills and Responsible Decision-Making), and the framework of 'SAFE' practices, which describes four essential features of effective SEL curricula (Sequenced, Active, Focused and Explicit) (Durlak, Weissberg, \& Pachan, 2010). KidsMatter in Australia (Littlefield, Cavanagh, Knapp, \& O'Grady, 2017) and the School Theory of Action (Meyers et al., 2015) are other initiatives that have been designed to support young people's mental health through SEL.

Empirical contributions. The utility of systematic SEL programming in fostering positive skills and wellbeing, and reducing negative youth outcomes, is well documented (Greenberg et al., 2003; Taylor, Oberle, Durlak, \& Weissberg, 2017). In a meta-analysis of findings from over 200 studies, students who received universal SEL education showed greater improvements in mental health, social-emotional competence and problem behaviours compared to those who did not (Durlak, Weissberg, Dymnicki, Taylor, \& Schellinger, 2011). Model SEL interventions, such as Promoting Alternative Thinking Strategies and Emotional Literacy in the Classroom, have been successfully implemented in schools and found to increase students' social and emotional skills (Elbertson, Brackett, \& Weissberg, 2010). The effectiveness of SEL has also been demonstrated in varying student populations and across different time periods, further attesting to the SEL's empirical contributions to promoting YWB (Payton et al., 2008).

Coaching and Mentoring Psychology. Coaching and mentoring are methodologies for improving wellbeing and performance in personal and professional life (Passmore, Peterson, \& Freire, 2016). Although CAMP can be viewed as separate initiatives (Passmore, 2007), they also share much common ground: both support individuals through times of transition and change, are associated with enhancing learning and development, and emphasise the importance of relationship quality in facilitator-client interactions (Garvey, Garvey, Stokes, \& Megginson, 2018). Depending on the specific intervention, CAMP may target diverse age groups (e.g., adults, young people), settings (e.g., clinical, non-clinical, workplace, school, community), and wellbeing domains (e.g., social, emotional, cognitive, psychological, physical, behavioural, academic) (Parsloe \& Leedham, 2016; Passmore et al., 2016).

Theoretical contributions. Coaching and Mentoring Psychology contributes an understanding of how YWB can be targeted and promoted by drawing upon existing theories and developing new frameworks. Within a positive psychology-based framework, for example, coaching may help individuals achieve greater levels of wellbeing by applying theories of flow, hope and character strengths to its practice (Kauffman, 2006). Based on learning theory, coaching can promote deep learning experiences by leading coachees through a process of knowledge discovery, realisation and integration (Griffiths \& Campbell, 2009). Within the context of mentoring, theories on young people's social-emotional, cognitive and identity development appear central to understanding the impact of mentoring relationships on youth outcomes (Rhodes, 2005). CAMP also develops new frameworks for structuring effective coaching and mentoring sessions that can be used with young people, including GROW (Whitmore, 2002) and the Multiple Mentor Model (Wright-Harp \& Cole, 2008).

Empirical contributions. Empirical evidence supports the efficacy of coaching and mentoring interventions in promoting YWB. Positive changes in students' levels of 
engagement, hope, resilience and depressive symptoms in response to coaching have been documented (Green, Grant, \& Rynsaardt, 2007; Madden, Green, \& Grant, 2011), and improvements in self-efficacy and self-confidence among youth coaches have been reported following the delivery of a near-peer coaching programme (Van Nieuwerburgh \& Tong, 2013). Moreover, compared to non-mentored youth, youth in longer-term mentoring relationships have shown to experience fewer behavioural problems, reduced levels of depression and social anxiety, and stronger coping skills (DeWit, DuBois, Erdem, Larose, \& Lipman, 2016). Although the effects of mentoring on YWB have not been consistently shown across studies (e.g., Heppen et al., 2017), specific programme practices and mentee characteristics appear to be important factors influencing the success of mentoring interventions (DuBois, Holloway, Valentine, \& Cooper, 2002). Additional evidence for the positive effects of mentoring on YWB is provided by DuBois, Portillo, Rhodes, Silverthorn, and Valentine (2011).

Quality of Life. As a unifying definition, QOL is a combination of objective and subjective wellbeing in multiple life domains (e.g., physical, social, emotional/spiritual, material, productive) valued in one's culture and time (Wallander, Schmitt, \& Koot, 2001). Although QOL research has largely focused on measuring adult QOL, more recent advances have been made in developing instruments to measure youth QOL, in both patient and general populations and settings (Wallander \& Koot, 2016). These advances can be classified under three main approaches: Health-Related QOL, Subjective Wellbeing and Social Indicators (for descriptions of these approaches, see Wallander \& Koot, 2016).

Theoretical contributions. Quality of Life provides a theoretical basis for understanding the domains most central to QOL and thus YWB. Health-related QOL instruments commonly measure concepts related to physical, psychological and social aspects of health (Solans et al., 2008), and tools designed to assess Subjective Wellbeing have represented YWB in terms of Life Satisfaction, Positive Affect and Meaning and Purpose (e.g., PROMIS; Ravens-Sieberer et al., 2014). Whereas health-related QOL and subjective wellbeing approaches tend to focus on subjective, individual-level indicators of YWB, Social Indicators seeks to provide more objective assessments at the national level that captures the impact of physical, psychological, cognitive, social and economic factors on QOL (Lippman, 2007). Theoretical models illustrating the relationships between psychological and psychosocial factors and health-related life quality in youth people have also been proposed (e.g., Gaspar et al., 2009). By providing insight into the individual and external factors comprising and affecting QOL, the field of QOL offers a broader, more contextual conceptualisation of YWB that distinguishes its work from other fields.

Empirical contributions. Conducting empirical research on the wellbeing correlates of life quality and using QOL instruments to track YWB status have been an important focus in the field. Health-related QOL has been associated with youth perceptions of life satisfaction, global self-esteem and health behaviours, and also with demographic characteristics such as gender, age, and socioeconomic status (Gaspar et al., 2009; Zullig, Valois, Huebner, \& Drane, 2005). As indicated by measures of Subjective Wellbeing and Social Indicators, other conditions that may influence YWB include living arrangement (Dinisman, Montserrat, \& Casas, 2012), chronic illness (Sawyer, Drew, Yeo, \& Britto, 2007) and ecological factors such as economic stability and advancements in medicine (Meadows, Land, \& Lamb, 2005). 
Summary. The YWB Fives each offer a unique vantage point from which to understand and promote YWB (see Table 1). For example, PE is distinguished by its focus on promoting the psychological, cognitive, social, emotional and spiritual aspects of YWB in school settings, whereas SEL prioritises building social, emotional and cognitive competencies in young people across both school and afterschool contexts. Still others target their research to a broader audience; PYD applies school, afterschool and community arenas, QOL produces research relevant to healthcare and general population settings, and CAMP is relevant to almost any youth setting in which positive change is desired. Despite individual differences, our review thus far has shown that YWB promotion is a common objective shared by the YWB Fives. To the extent that fields working towards shared objectives may have a strong incentive to collaborate, one might find evidence for intersections to exist among the YWB Fives. The next section examines this possibility by reviewing evidence on their collective contributions to promoting YWB.

\section{Collective Contributions of the Youth Wellbeing Fives}

The collective contributions of the YWB Fives are supported by three main observations: (1) concepts pertinent to YWB overlap across the YWB Fives, (2) the approaches offered by multiple YWB Fives complement one another, and (3) the knowledge and expertise of multiple YWB Fives can be integrated to strengthen YWB research and YWB as a construct more specifically.

Substantial overlap can be found across the YWB Fives, as indicated by their discussions of many similar concepts related to YWB; for example, resilience (e.g., Green et al., 2007; Seligman et al., 2009), relationships (e.g., Rhodes, 2005; Waters, 2011), life satisfaction (e.g., Proctor et al., 2011; Zullig et al., 2005) and notions of competence and mastery (e.g., Durlak et al., 2011; Lerner, 2004). Support for their collective contributions is also shown in their complementary approaches to YWB science. To illustrate, SEL and PYD have a shared orientation towards strengths and adaptation as opposed to weaknesses and psychopathology (Tolan et al., 2016), a perspective that also characterises the work of PE (Norrish \& VellaBrodrick, 2009) and complements coaching practice in its delivery of successful interventions designed to foster YWB (e.g., Green \& Norrish, 2013; Madden et al., 2011). The fields of PE and QOL also share similar, 'comprehensive' approaches to YWB, in which YWB is conceptualised as comprising both positive and negative components (Wallander \& Koot, 2016; Waters, 2017).

Research also suggests that harnessing the knowledge and expertise of multiple YWB Fives can strengthen YWB research and YWB specifically. The finding that emotion regulation shapes the effects of PE participation on student wellbeing (Morrish, Rickard, Chin, \& VellaBrodrick, 2017), for instance, illustrates the benefits of understanding SEL for evaluating effective PE interventions. Other findings, such as CAMP's influence on promoting constructs consistent with positive psychology theory in young people (e.g., hope) (Green et al., 2007), highlight the ability of collective approaches to advance YWB science by validating its key theoretical constructs. Scholars have additionally proposed integrating the theoretical knowledge of PYD into mentoring programmes (Silva \& Freire, 2014) and drawing upon PYD's expertise to assist SEL intervention delivery in schoolhouses (Elias et al., 2015), while others have advocated combining CAMP and PE approaches to promote YWB (Green, Oades, \& 
Robinson, 2012). Some practical implications arising from these findings centre on the potential benefits of integrating frameworks drawn from different YWB Five literatures, and implementing school wellbeing interventions that include features of different approaches. In this regard, schools embracing an existing positive education framework could adopt PYD principles to enhance their teaching curricula, or integrate CAMP techniques in positive psychology interventions to enhance program efficacy.

\section{Discussion}

In developing a cross-disciplinary framework for promoting $\mathrm{YWB}$, we presented the argument of moving beyond the boundaries of single fields given the potential for integrated approaches to achieve a greater understanding of $\mathrm{YWB}$, solve the grand challenge of promoting YWB and maximise the quality, impact and efficiency of YWB research. In this review, we identified the YWB Fives as five major fields driving the advancement of YWB and provided a snapshot of their individual and collective contributions to promoting YWB. Taken together, the extant literature supports the unique and complementary ways in which the YWB Fives contribute to the theoretical, conceptual and empirical underpinnings of YWB promotion.

Several limitations of this review should be considered. Firstly, PE, PYD, SEL, CAMP and QOL were subjectively selected as fields central to promoting YWB. Although outside the scope of the present paper, it would be useful for future youth studies to undertake a more systematic, objective approach to identifying the fields most central to YWB scholarship, such as by searching the literature for relevant articles and basing one's selection of fields on measures such as frequency or quality of their publications. It should also be noted that, in recognising the centrality of the YWB Fives to the YWB literature, by no means do we imply that the YWB literature draws exclusively from these fields. This paper started with five core fields however future work could include other fields and labels. Thus it is important for researchers to remain vigilant of other areas gaining momentum in YWB literature; Character Education, for example, is one such field that could be considered a possible addition to the existing YWB Fives.

Secondly, we acknowledge that our review largely summarised the evidence in favour of rather than against cross-disciplinary collaboration between the YWB Fives. Our reason for focusing on the former was that the collective contributions of the YWB Fives to promoting YWB had not been well understood previously and represented a relatively new and uncharted territory to be explored. Nonetheless, despite little attention paid to the challenges of crossdisciplinary integration, it is important to clarify that vertical growth - as in the case of conducting research into specific areas in depth - and horizontal growth - as in the case of synthesising knowledge across multiple fields to expand research to new fronts - are both equally important and should occur simultaneously to ensure the continuous and optimal development of scientific research.

Finally, our conclusions about the possibility of intersections to exist among the YWB Fives were derived conceptually rather than empirically. Although scholars have noted the relative lack of integration between fields focused on wellbeing (e.g., Tolan et al., 2016), it remains to be statistically determined whether the YWB Fives intersect, if at all, within the 
actual literature. This limitation may be overcome by developing and gathering objective metrics designed to measure intersectionality.

Keeping in mind these limitations, our findings suggest that the YWB literature is inherently cross-disciplinary. Thus efforts to promote YWB would benefit from looking at the breadth of evidence offered by multiple fields, such as the YWB Fives, and drawing upon their expertise to paint a more complete picture of YWB. These insights yield important implications for future research and practice; they encourage future youth studies to more consciously move beyond considering how their work impacts research within their own fields, to considering how it may connect more broadly with the academic work of other related fields. Insights gained from this review also provide a strong conceptual rationale for future scholars to empirically measure the levels of intersection - and thus collective contributions -among the YWB Fives. Another avenue to be explored in future research and practice is the development, delivery and evaluation of cross-disciplinary YWB interventions. Cross-disciplinary interventions may play a vital role in providing young people with widespread access to wellbeing services, such as by incorporating features informed by multiple fields that enable the intervention to target a broader set of wellbeing constructs and apply to a wider audience and range of settings. Accordingly, we encourage researchers, practitioners and other invested stakeholders to work together in implementing rigorous, cross-disciplinary interventions that consistently demonstrate positive youth outcomes. By embracing a cross-disciplinary approach, we can more effectively support the wellbeing of youth today and ensure that our generation of young people continues to flourish in everyday life.

\section{Authors}

Amanda Ng

University of Melbourne

ng.a@unimelb.edu.au

Dianne Vella-Brodrick

University of Melbourne

\section{Publishing Timeline}

Received 14 May 2019

Accepted 23 September 2019

Published 26 September 2019

\section{Author Note}

Preliminary work on this paper was presented at a workshop during the 2016 Positive Education Conference Perth, Perth College, WA Australia 6050. The authors declare no financial benefit arising from this research, however would like to disclose a conflict of interest with Associate Professor Aaron Jarden and Dr. Gavin Slemp from the International Journal of Wellbeing editorial team, who are colleagues of the authors and affiliated with the Centre for Positive Psychology at the University of Melbourne. 


\section{References}

Barjak, F., \& Robinson, S. (2008). International Collaboration, Mobility and Team Diversity in the Life Sciences: Impact on Research Performance. Social Geography, 3(1), 23-36.

Benson, P. L., Scales, P. C., Hamilton, S. F., \& Sesma, A. (2006). Positive Youth Development: Theory, Research, and Applications. In W. Damon \& R. M. Lerner (Eds.), Handbook of Child Psychology: Theoretical Models of Human Development (6th ed., Vol. 1, pp. 894-941). New York: Wiley \& Sons.

Bobek, D., Zaff, J., Li, Y., \& Lerner, R. M. (2009). Cognitive, Emotional, and Behavioral Components of Civic Action: Towards an Integrated Measure of Civic Engagement. Journal of Applied Developmental Psychology, 30(5), 615-627.

Catalano, R. F., Berglund, M. L., Ryan, J. A. M., Lonczak, H. S., \& Hawkins, J. D. (2004). Positive Youth Development in the United States: Research Findings on Evaluations of Positive Youth Development Programs. The Annals of the American Academy of Political and Social Science, 591(1), 98-124.

Ciocanel, O., Power, K., Eriksen, A., \& Gillings, K. (2017). Effectiveness of Positive Youth Development Interventions: A Meta-Analysis of Randomized Controlled Trials. Journal of Youth and Adolescence, 46(3), 483-504.

Collaborative for Academic Social and Emotional Learning. (2005). Safe and Sound: An Educational Leader's Guide to Evidence-Based Social and Emotional Learning Programs-Illinois Edition. Chicago: CASEL.

Cummings, J. N., \& Kiesler, S. (2007). Coordination Costs and Project Outcomes in Multi-University Collaborations. Research Policy, 36(10), 1620-1634.

DeWit, D. J., DuBois, D., Erdem, G., Larose, S., \& Lipman, E. L. (2016). The Role of Program-Supported Mentoring Relationships in Promoting Youth Mental Health, Behavioral and Developmental Outcomes. Prevention Science, 17(5), 646-657.

Dinisman, T., Montserrat, C., \& Casas, F. (2012). The Subjective Well-Being of Spanish Adolescents: Variations According to Different Living Arrangements. Children and Youth Services Review, 34(12), 2374-2380.

DuBois, D. L., Holloway, B. E., Valentine, J. C., \& Cooper, H. (2002). Effectiveness of Mentoring Programs for Youth: A Meta-Analytic Review. American Journal of Community Psychology, 30(2), 157-197.

DuBois, D. L., Portillo, N., Rhodes, J. E., Silverthorn, N., \& Valentine, J. C. (2011). How Effective are Mentoring Programs for Youth? A Systematic Assessment of the Evidence. Psychological Science in the Public Interest, 12(2), 57-91.

Durlak, J. A., Weissberg, R. P., Dymnicki, A. B., Taylor, R. D., \& Schellinger, K. B. (2011). The Impact of Enhancing Students' Social and Emotional Learning: A Meta-Analysis of School-Based Universal Interventions. Child Development, 82(1), 405-432.

Durlak, J. A., Weissberg, R. P., \& Pachan, M. (2010). A Meta-Analysis of After-School Programs that Seek to Promote Personal and Social Skills in Children and Adolescents. American Journal of Community Psychology, 45(3-4), 294-309.

Eccles, J., \& Gootman, J., eds. (2002). Community Programs to Promote Youth Development. Washington, DC: The National Academies Press.

Eckersley, R. (2011). A New Narrative of Young People's Health and Well-Being. Journal of Youth Studies, 14(5), 627-638.

Eichas, K., Albrecht, R. E., Garcia, A. J., Ritchie, R. A., Varela, A., Garcia, A., . . Silverman, W. K. (2010). Mediators of Positive Youth Development Intervention Change: Promoting Change in Positive and Problem Outcomes? Child Youth Care Forum, 39(4), 211-237.

Elbertson, N. A., Brackett, M. A., \& Weissberg, R. P. (2010). School-Based Social and Emotional Learning (SEL) Programming: Current Perspectives. In A. Hargreaves, A. Lieberman, M. G. Fullan, \& D. Hopkins (Eds.), Second International Handbook of Educational Change (pp. 1017-1032). Dordrecht: Springer. 
Elias, M. J., Leverett, L., Duffell, J., Humphrey, N., Stepney, C. T., \& Ferrito, J. J. (2015). Integrating SocialEmotional Learning with Related Prevention and Youth-Development Approaches. In J. A. Durlak, C. Domitrovich, R. P. Weissberg, \& T. P. Gullotta (Eds.), Handbook of Social and Emotional Learning: Research and Practice. New York: Guildford.

Franceschet, M., \& Costantini, A. (2010). The Effect of Scholar Collaboration on Impact and Quality of Academic Papers. Journal of Informetrics, 4(4), 540-553.

Fredrickson, B. (2001). The Role of Positive Emotions in Positive Psychology: The Broaden-and-Build Theory of Positive Emotions. American Psychologist, 56(3), 218-226.

Garvey, B., Garvey, R., Stokes, P., \& Megginson, D. (2018). Coaching and Mentoring: Theory and Practice (3rd ed.). London: Sage Publications.

Gaspar, T., Matos, M. G., Pais, R., José, L., Leal, I., \& Ferreira, A. (2009). Health-Related Quality of Life in Children and Adolescents and Associated Factors. Journal of Cognitive and Behavioral Psychotherapies, 9(1), 33-48.

Gigantesco, A., Stazi, M. A., Alessandri, G., Medda, E., Tarolla, E., \& Fagnani, C. (2011). Psychological Well-Being (PWB): A Natural Life Outlook? An Italian Twin Study on Heritability of PWB in Young Adults. Psychological Medicine, 41(12), 2637-2649.

Green, L. S., \& Norrish, J. M. (2013). Enhancing Well-Being in Adolescents: Positive Psychology and Coaching Psychology Interventions in Schools. In C. Proctor \& A. Linley (Eds.), Research, Applications, and Interventions for Children and Adolescents (pp. 211-222). Dordrecht: Springer.

Green, L. S., Oades, L. G., \& Robinson, P. L. (2012). Positive Education Programmes: Integrating Coaching and Positive Psychology in Schools. In C. V. Nieuwerburgh (Ed.), Coaching in Education: Getting Better Results for Students, Educators, and Parents (pp. 115-132). London: Karnac Books.

Green, S., Grant, A. M., \& Rynsaardt, J. (2007). Evidence-Based Life Coaching for Senior High School Students: Building Hardiness and Hope. International Coaching Psychology Review, 2(1), 24-32.

Greenberg, M. T., Weissberg, R. P., O'brien, M. U., Zins, J. E., Fredericks, L., Resnik, H., \& Elias, M. J. (2003). Enhancing School-Based Prevention and Youth Development Through Coordinated Social, Emotional, and Academic Learning. American Psychologist, 58(6-7), 466-474.

Griffiths, K. E., \& Campbell, M. A. (2009). Discovering, Applying and Integrating: The Process of Learning in Coaching. International Journal of Evidence Based Coaching and Mentoring, 7(2), 16-30.

Hackett, E. J., Parker, J. N., Conz, D., Rhoten, D., \& Parker, A. (2008). Ecology Transformed: The National Center for Ecological Analysis and Synthesis and the Changing Patterns of Ecological Research. In G. M. Olson, A. Zimmerman, \& N. Bos (Eds.), Scientific Collaboration on the Internet (pp. 277-296). Cambridge: MIT Press.

Heck, K. E., \& Subramaniam, A. (2009). Youth Development Frameworks. Davis: 4-H Center for Youth Development, University of California.

Heppen, J. B., Zeiser, K., Holtzman, D. J., O'Cummings, M., Christenson, S., \& Pohl, A. (2017). Efficacy of the Check \& Connect Mentoring Program for At-Risk General Education High School Students. Journal of Research on Educational Effectiveness, 1-27. Advanced online publication.

Hoyt, L. T., Chase-Lansdale, P. L., McDade, T. W., \& Adam, E. K. (2012). Positive Youth, Healthy Adults: Does Positive Well-Being in Adolescence Predict Better Perceived Health and Fewer Risky Health Behaviors in Young Adulthood? Journal of Adolescent Health, 50(1), 66-73.

Humphrey, N., ed. (2013). Social and Emotional Learning: A Critical Appraisal. Thousand Oaks: Sage Publications.

Huppert, F. A. (2009). Psychological Well-Being: Evidence Regarding Its Causes and Consequences. Applied Psychology: Health and Well-Being, 1(2), 137-164. 
Jarden, A., \& Jarden, R. (2015). Applied Positive Psychology in Higher Education. In M. A. Henning, C. U. Krägeloh, \& G. Wong-Toi (Eds.), Student Motivation and Quality of Life in Higher Education (Rev. ed., pp. 37-44). London: Routledge.

Jeffrey, P. (2003). Smoothing the Waters: Observations on the Process of Cross-Disciplinary Research Collaboration. Social Studies of Science, 33(4), 539-562.

Jelicic, H., Bobek, D. L., Phelps, E., Lerner, R. M., \& Lerner, J. V. (2007). Using Positive Youth Development to Predict Contribution and Risk Behaviors in Early Adolescence: Findings from the First Two Waves of the 4-H Study of Positive Youth Development. International Journal of Behavioral Development, 31(3), 263-273.

Kauffman, C. (2006). Positive Psychology: The Science at the Heart of Coaching. In D. R. Stober \& A. Grant (Eds.), Evidence Based Coaching Handbook: Putting Best Practices to Work for Your Clients (pp. 219253). Hoboken: Wiley \& Sons.

Kern, M. L., Waters, L., Adler, A., \& White, M. A. (2015). A multidimensional approach to measuring well-being in students: Application of the PERMA framework. The Journal of Positive Psychology, 10(3), 262-271.

Knapp, B., Bardenet, R., Bernabeu, M. O., Bordas, R., Bruna, M., Calderhead, B., . . . Kuijper, B. (2015). Ten Simple Rules for a Successful Cross-Disciplinary Collaboration. PLoS Computational Biology, 11(4), e1004214.

Kress, C. (2003). The Circle of Courage in Practice: The 4-H Club Study 1. Reclaiming Children and Youth, 12(1), 27.

Lerner, R. M. (2004). Liberty: Thriving and Civic Engagement Among America's Youth. Thousand Oaks: Sage Publications.

Lilienfeld, S. O., Sauvigné, K. C., Lynn, S. J., Cautin, R. L., Latzman, R. D., \& Waldman, I. D. (2015). Fifty Psychological and Psychiatric Terms to Avoid: A List of Inaccurate, Misleading, Misused, Ambiguous, and Logically Confused Words and Phrases. Frontiers in Psychology, 6.

Lippman, L. H. (2007). Indicators and Indices of Child Well-Being: A Brief American History. Social Indicators Research, 83(1), 39-53.

Littlefield, L., Cavanagh, S., Knapp, R., \& O'Grady, L. (2017). KidsMatter: Building the Capacity of Australian Primary Schools and Early Childhood Services to Foster Children's Social and Emotional Skills and Promote Children's Mental Health. In E. Frydenberg, A. J. Martin, \& R. J. Collie (Eds.), Social and Emotional Learning in Australia and the Asia-Pacific (pp. 293-311). Singapore: Springer.

Madden, W., Green, S., \& Grant, A. M. (2011). A Pilot Study Evaluating Strengths-Based Coaching for Primary School Students: Enhancing Engagement and Hope. International Coaching Psychology Review, 6(1), 71-83.

McLeod, J., \& Wright, K. (2016). What Does Wellbeing Do? An Approach to Defamiliarize Keywords in Youth Studies. Journal of Youth Studies, 19(6), 776-792.

Meadows, S. O., Land, K. C., \& Lamb, V. L. (2005). Assessing Gilligan vs. Sommers: Gender-Specific Trends in Child and Youth Well-Being in the United States, 1985-2001. Social Indicators Research, 70(1), 1-52.

Meyers, D. C., Gil, L., Cross, R., Keister, S., Domitrovich, C. E., \& Weissberg, R. P. (2015). CASEL Guide for Schoolwide Social and Emotional Learning. Chicago: CASEL.

Milnes, A., Pegrum, K., Nebe, B., Topfer, A., Gaal, L., Zhang, J., \& Hunter, N. (2011). Young Australians: Their Health and Wellbeing 2011. Canberra: Australian Institute of Health and Welfare.

Morrish, L., Rickard, N., Chin, T.-C., \& Vella-Brodrick, D. A. (2017). Emotion Regulation in Adolescent Well-being and Positive Education. Journal of Happiness Studies, 19(5), 1543-1564. 
Nakamura, J., \& Csikszentmihalyi, M. (2009). Flow Theory and Research. In S. J. Lopez \& C. R. Snyder (Eds.), The Oxford Handbook of Positive Psychology (2nd ed., pp. 195-206). New York: Oxford University Press.

Noble, T., \& McGrath, H. (2008). The Positive Educational Practices Framework: A Tool for Facilitating the Work of Educational Psychologists in Promoting Pupil Wellbeing. Educational and Child Psychology, 25(2), 119-134.

Noble, T., \& McGrath, H. (2015). PROSPER: A New Framework for Positive Education. Psychology of Well-Being, 5(2), 1-17.

Norrish, J. M., \& Vella-Brodrick, D. A. (2009). Positive Psychology and Adolescents: Where Are We Now? Where to From Here? Australian Psychologist, 44(4), 270-278.

Norrish, J. M., Williams, P., O'Connor, M., \& Robinson, J. (2013). An Applied Framework for Positive Education. International Journal of Wellbeing, 3(2), 147-161.

O'Rourke, M., Crowley, S., \& Gonnerman, C. (2016). On the Nature of Cross-Disciplinary Integration: A Philosophical Framework. Studies in History and Philosophy of Science Part C: Studies in History and Philosophy of Biological and Biomedical Sciences, 56, 62-70. doi:10.1016/j.shpsc.2015.10.003

Oades, L. G., Robinson, P., \& Green, S. (2011). Positive Education: Creating Flourishing Students, Staff and Schools. InPsych, 33(2), 16-17.

Olsson, C. A., McGee, R., Nada-Raja, S., \& Williams, S. M. (2013). A 32-Year Longitudinal Study of Child and Adolescent Pathways to Well-Being in Adulthood. Journal of Happiness Studies, 14(3), 1069-1083.

Osher, D., Kidron, Y., Brackett, M., Dymnicki, A., Jones, S., \& Weissberg, R. P. (2016). Advancing the Science and Practice of Social and Emotional Learning: Looking Back and Moving Forward. Review of Research in Education, 40(1), 644-681.

Parsloe, E., \& Leedham, M. (2016). Coaching and Mentoring: Practical Techniques for Developing Learning and Performance (D. Newell Ed. 3rd ed.). London: Kogan Page.

Passmore, J. (2007). Coaching and Mentoring: The Role of Experience and Sector Knowledge. International Journal of Evidence Based Coaching and Mentoring, 5, 10-16.

Passmore, J., Peterson, D., \& Freire, T., eds. (2016). The Wiley-Blackwell Handbook of the Psychology of Coaching and Mentoring. New York: Wiley \& Sons.

Patton, G. C., Coffey, C., Cappa, C., Currie, D., Riley, L., Gore, F., . . Sangowawa, A. O. (2012). Health of the World's Adolescents: A Synthesis of Internationally Comparable Data. The Lancet, 379, 1665-1675. doi:10.1016/S0140-6736(12)60203-7

Payton, J., Weissberg, R. P., Durlak, J. A., Dymnicki, A. B., Taylor, R. D., Schellinger, K. B., \& Pachan, M. (2008). The Positive Impact of Social and Emotional Learning for Kindergarten to Eighth-Grade Students: Findings from Three Scientific Reviews. Chicago: CASEL.

Peterson, C., \& Seligman, M. E. P. (2006). The Values in Action (VIA) Classification of Strengths. In M. Csikszentmihalyi \& S. Csikszentmihalyi (Eds.), A life worth living: Contributions to positive psychology (pp. 29-48). New York: Oxford University Press.

Porter, A. L., Garner, J., \& Crowl, T. (2012). Research Coordination Networks: Evidence of the Relationship Between Funded Interdisciplinary Networking and Scholarly Impact. Bioscience, 62(3), 282-288.

Proctor, C., Tsukayama, E., Wood, A. M., Maltby, J., Eades, J. F., \& Linley, P. A. (2011). Strengths Gym: The Impact of a Character Strengths-Based Intervention on the Life Satisfaction and Well-Being of Adolescents. The Journal of Positive Psychology, 6(5), 377-388.

Ravens-Sieberer, U., Devine, J., Bevans, K., Riley, A. W., Moon, J., Salsman, J. M., \& Forrest, C. B. (2014). Subjective Well-Being Measures for Children Were Developed Within the PROMIS Project: Presentation of First Results. Journal of Clinical Epidemiology, 67(2), 207-218. 
Reschly, A. L., Huebner, E. S., Appleton, J. J., \& Antaramian, S. (2008). Engagement as Flourishing: The Contribution of Positive Emotions and Coping to Adolescents' Engagement at School and with Learning. Psychology in the Schools, 45(5), 419-431.

Rhodes, J. E. (2005). A Model of Youth Mentoring. In D. L. DuBois \& M. J. Karcher (Eds.), Handbook of Youth Mentoring (pp. 30-43). Thousand Oaks: Sage Publications.

Roth, J. L., \& Brooks-Gunn, J. (2003). What Exactly is a Youth Development Program? Answers from Research and Practice. Applied Developmental Science, 7(2), 94-111.

Sapienza, J. K., \& Masten, A. S. (2011). Understanding and Promoting Resilience in Children and Youth. Current Opinion in Psychiatry, 24(4), 267-273.

Sawyer, S. M., Drew, S., Yeo, M. S., \& Britto, M. T. (2007). Adolescents with a Chronic Condition: Challenges Living, Challenges Treating. The Lancet, 369(9571), 1481-1489.

Seligman, M. E. P., Ernst, R. M., Gillham, J., Reivich, K., \& Linkins, M. (2009). Positive Education: Positive Psychology and Classroom Interventions. Oxford Review of Education, 35(3), 293-311.

Silva, E., \& Freire, T. (2014). Mentoring Programs and Promotion of Positive Youth Development. Revista Portuguesa de Educação, 27(1), 157-176.

Slemp, G. R., Chin, T.-C., Kern, M. L., Siokou, C., Loton, D., Oades, L. G., . . Waters, L. (2017). Positive Education in Australia: Practice, Measurement, and Future Directions. In E. Frydenberg, A. J. Martin, \& R. J. Collie (Eds.), Social and Emotional Learning in Australia and the Asia-Pacific (pp. 101-122). Singapore: Springer.

Solans, M., Pane, S., Estrada, M., Serra-Sutton, V., Berra, S., Herdman, M., . . Rajmil, L. (2008). HealthRelated Quality of Life Measurement in Children and Adolescents: A Systematic Review of Generic and Disease-Specific Instruments. Value in Health, 11(4), 742-764.

Sukarieh, M., \& Tannock, S. (2011). The Positivity Imperative: A Critical Look at the 'New' Youth Development Movement. Journal of Youth Studies, 14(6), 675-691.

Sumner, R., Burrow, A. L., \& Hill, P. L. (2015). Identity and Purpose as Predictors of Subjective WellBeing in Emerging Adulthood. Emerging Adulthood, 3(1), 46-54.

Taylor, R. D., Oberle, E., Durlak, J. A., \& Weissberg, R. P. (2017). Promoting Positive Youth Development Through School-Based Social and Emotional Learning Interventions: A Meta-Analysis of Follow-Up Effects. Child Development, 88(4), 1156-1171.

Tebes, J. K., Feinn, R., Vanderploeg, J. J., Chinman, M. J., Shepard, J., Brabham, T., . . Connell, C. (2007). Impact of a Positive Youth Development Program in Urban After-School Settings on the Prevention of Adolescent Substance Use. Journal of Adolescent Health, 41(3), 239-247.

Tolan, P., Ross, K., Arkin, N., Godine, N., \& Clark, E. (2016). Toward an Integrated Approach to Positive Development: Implications for Intervention. Applied Developmental Science, 20(3), 214-236.

Van Nieuwerburgh, C. (Ed.) (2012). Coaching in education: Getting better results for students, educators, and parents. London: Karnac Books.

Van Nieuwerburgh, C., \& Tong, C. (2013). Exploring the Benefits of Being a Student Coach in Educational Settings: A Mixed-Method Study. Coaching: An International Journal of Theory, Research and Practice, 6(1), 5-24.

Vella-Brodrick, D. A., Rickard, N., \& Chin, T. (August 2014). An Evaluation of Positive Education at Geelong Grammar School: A Snapshot of 2013. The University Of Melbourne, VIC, Australia.

Vicens, Q., \& Bourne, P. E. (2007). Ten Simple Rules for a Successful Collaboration. PLoS Computational Biology, 3(3), e44.

Wallander, J. L., \& Koot, H. M. (2016). Quality of Life in Children: A Critical Examination of Concepts, Approaches, Issues, and Future Directions. Clinical Psychology Review, 45, 131-143.

Wallander, J. L., Schmitt, M., \& Koot, H. M. (2001). Quality of Life Measurement in Children and Adolescents: Issues, Instruments, and Applications. Journal of Clinical Psychology, 57(4), 571-585. 
Waters, L. (2011). A Review of School-Based Positive Psychology Interventions. The Australian Educational and Developmental Psychologist, 28(2), 75-90.

Waters, L. (2017). Progressing Positive Education and Promoting Visible Well-Being in Schools. In M. A. Warren \& S. I. Donaldson (Eds.), Scientific Advances in Positive Psychology (pp. 229-255). Santa Barbara: Praeger.

Whitmore, J. (2002). Coaching for Performance: GROWing People, Perfomance and Purpose. Boston: Nicholas Brealey Publishing.

Wright-Harp, W., \& Cole, P. A. (2008). A Mentoring Model for Enhancing Success in Graduate Education. Contemporary Issues in Communication Science \& Disorders, 35, 4-16.

Zins, J. E., \& Elias, M. J. (2007). Social and Emotional Learning: Promoting the Development of All Students. Journal of Educational and Psychological Consultation, 17(2-3), 233-255.

Zullig, K. J., Valois, R. F., Huebner, E. S., \& Drane, J. W. (2005). Adolescent Health-Related Quality of Life and Perceived Satisfaction with Life. Quality of Life Research, 14(6), 1573-1584. 